\title{
RECENT ADVANCES IN THE TREATMENT OF MALIGNANT MELANOMA WITH GENE THERAPY
}

\author{
Evan M. Hersh and Alison T. Stopeck \\ Arizona Cancer Center, Tucson, Arizona
}

Malignant melanoma is a growing problem. In 1997 there will be in excess of 40,000 cases of malignant melanoma in the United States, with 7300 deaths occurring (1). The incidence has been increasing by $5 \%$ per year for the last 40 years. Interestingly, the survival rate has also improved by almost $5 \%$ per year (2). The overall survival rate has gone from $60 \%$ to over $80 \%$ during this period. The prognostic variables that predict for a high likelihood of relapse among patients with primary cutaneous melanoma or regional lymph nodes recurrences are well established (3). Thus, there are well-defined groups of patients who can be targeted for biological therapy and gene therapy to prevent relapse. The immunological characteristics of malignant melanoma have been studied extensively and can be used to develop approaches to immunotherapy (4). Tumor-associated or tumor-specific antigens have been described at the molecular level (5). These can induce specific cytotoxic T cell (CTL) and antibody responses. This natural immune reactivity has provided the foundation for biological and gene therapy of melanoma. There is also abundant data that both general immunocompetence and specific immune reactivity to melanoma predict for a good prognosis (6). Recently, molecular mechanisms have been described that explain how melanoma and other cancers evade the immune response and why anti-tumor host defense mechanisms fail. These provide additional targets for biological and gene therapy of melanoma.

Address correspondence and reprint requests to Dr. Evan M. Hersh, Arizona Cancer Center, 1515 North Campbell Avenue, P.O. Box 245024, Tucson, AZ 85724-5024. Phone: 520-626-2250; Fax: 520-626-2225; e-mail: hersh@azcc. arizona.edu.

\section{TUMOR ANTIGENS IN MELANOMA}

Tumor antigens have been studied intensively in malignant melanoma since the mid-1970s. Melanoma-associated antigens (MAA) were initially defined by reactivity of melanoma patients' sera against autologous and allogeneic melanoma cell lines. Through these studies, pioneered by Lloyd Old and co-workers, individual specific tumor antigens, common melanoma-associated antigens, and antigens cross-reactive with other tumors were recognized (7-9). Subsequently, murine (10) and human (11) monoclonal antibodies were used to identify both cell membrane and cytoplasmic MAA. The development of CTL lines manifesting MHC class I-restricted cytotoxicity to autologous and allogeneic melanoma cells (12) led to the definition of a group of MAA, to the cloning of their genes, and to their use in active specific immunotherapy and gene therapy experiments (13). MAA have been defined as lineage-specific, that is, they are limited to melanocytes and their precursors; to tumor progression antigens detected mainly in metastatic rather than primary melanomas, thus indicating a poor prognosis; and to $T$ cell-recognized antigens, also referred to as cancer regression antigens (14). Tyrosinase (15), gp-75 (16), high molecular weight MAA (HMW-MAA, gp-250, or chondroitin sulfate proteoglycan) (17) have been defined as lineage-specific. Progression antigens include MHC class II (HLA-DR) (18), epidermal growth factor (EGF) receptor (19), transferrin receptor (P97) (20), the integrins $\alpha 5 \beta 3$ (21), and Muc 18 (22).

Since 1991 a growing number of MAA have been defined by cloning the genes for antigens recognized by CTL lines. This strategy, initially developed by Boon and colleagues (12) and ex- 
panded by Rosenberg and colleagues (23), is important since these tumor rejection antigens can be exploited for biological and gene therapy. These antigens fall into several groups, including the MAGE, BAGE, and GAGE antigens, which are also found in other cancers $(24,25)$; tyrosinase $(15,16)$, gp100 (26), MelanA/MART-1 (27), and pMell7; and CDK4, MUM1, $\beta$ Catenin, GNT-V, and P15 (28). Another strategy to define MAA is to extract immunogeneic peptides from the MHC proteins of tumor lines, to characterize these by tandem mass spectroscopy and chromatography, and to test CTL reactive against T2 cells charged with the resultant peptides. This strategy has been carried out successfully (29).

With this plethora of antigens, a variety of strategies for biological and gene therapy have been attempted (30). These include (1) active specific immunotherapy with antigen or immunogeneic peptide alone, with adjuvant, or as an immunoconjugate to a carrier protein; (2) immunization with plasmid DNA expressing the immunodominant peptide; (3) immunization with viral constructs expressing the peptide; (4) in vitro or in vivo-in vitro generation of CTL followed by in vitro expansion and adoptive immunotherapy; and (5) gene therapy with activated T cells transduced with the antigen-specific $\mathrm{T}$ cell receptor (TCR).

\section{EVASION OF HOST CONTROL}

Melanoma cells are poor antigen-presenting cells. The majority of primary melanomas express HLA class I antigens but about half of metastatic melanomas lose this antigen expression (31). In murine B 16 melanoma, tumor-infiltrating lymphocytes (TIL) isolated from class I-negative tumors do not lyse tumor cells and have no therapeutic activity compared with TIL from class I-positive tumors (32). Upregulation of class I by interferon $\gamma($ IFN- $\gamma$ ) is a therapeutic strategy based on such findings (33). Melanoma cells and other solid tumors fail to express the costimulatory molecule B7.1 which is necessary for effective antigen presentation and stimulation of CTL responses. Transfection of B7.1 into murine melanoma results in increased immunogenicity, loss of tumorigenicity, and resistance to subsequent rechallenge with wild-type tumor (34). Interleukin 10 (IL-10) is a negative regulatory cytokine produced by a variety of cells (35). It promotes $\mathrm{TH} 2$ cell activity and down-regulates the $\mathrm{TH} \mathrm{l}$ response necessary for the generation of
CTL. Several human melanoma cell lines and fresh melanoma cell preparations express IL-10 mRNA and secrete IL-10 protein $(36,37)$. Furthermore, elevated IL-10 levels have been identified in the blood of patients with metastatic melanoma (37). Thus IL-10 is a possible target for IL-10 antibody, antisense, or ribozyme therapy. Many tumors also secrete transforming growth factor $\beta$ (TGF- $\beta$ ). It promotes angiogenesis and extracellular adhesion, and it inhibits mitogen and cytokine-induced $\mathrm{T}$ cell proliferation, the antibody response, and generation of cytotoxic lymphokine-activated killer (LAK) and CTL cells (38). We have shown that murine breast cancer cells transduced with TGF- $\beta$ antisense have reduced TGF- $\beta$ production and tumorigenicity. Mice that have rejected such transformed cells are resistant to subsequent challenge with wild-type cells (39). Another substance secreted by melanoma cells and other tumors is SPARC (secreted protein, acidic and rich in cysteine), a glycoprotein involved in wound healing (40). It is a counteradhesive molecule that promotes matrix metalloproteinase action and angiogenesis. Recently, human melanoma cells transduced with antisense to SPARC were shown to lose their tumorigenicity when implanted in athymic mice (41).

Tumors also evade host control by exploiting the fas system, a regulatory system for lymphocytes proliferation. CTL and natural killer (NK) cells use this as one mechanism of target cell killing (42). Activated lymphocytes express fas ligand that interacts with fas on target cells and triggers apoptotic cell death. This is one of the three mechanisms for CTL killing, the others being release of perforins and granzymes (43) and TNF- $\alpha$ plus IFN- $\gamma(44)$. Tumor cells may also express fas ligand and its expression may be upregulated by chemotherapy (45). Fas ligand expressing human melanoma cells has been shown to induce apoptosis in a fas-bearing lymphoma cell line (46). Fas ligand has been found on human melanoma (47), in hepatoma, and hepatic damage $(45,48)$, on colon polyps $(49)$, and on colon cancer (50). Stromal cells of the eye and sertoli cells of the testes also express high levels of fas ligand, which may explain these organs' immune privileged status (51). Certain tumor antigens can also induce apoptoses in activated lymphocytes (DF3Mucl) (52). Growth of fas ligand-positive murine melanoma is retarded in fas-deficient lpr mice, which suggests that when the invading CTL cannot be killed by the fas ligand-fas mechanism, effective CTL-mediated 
anti-tumor immunity is retained (53). Thus, the fas ligand system provides an attractive target for gene therapy of melanoma. Antibody antisense, or ribozymes directed to inactivate fas ligand, might all be effective in preventing killing of CTL by tumor cells.

A variety of mechanisms of host defense failure have been described in cancer patients. Recently in tumor-bearing mice and patients with a variety of malignancies, including cervical cancer, renal cancer, and melanoma, a structural abnormality in signal transducing zeta chains of CD3 and CD16 has been reported (54). This is associated with decreased lymphocyte cytokine response. Furthermore, survival in melanoma patients correlates with the level of TCR zeta chain (55). Impaired $T$ cell function in cancer patients can also be overcome by IL-12. Longterm IL-2 treatment increases the number and activity of NK cells in cancer patients post-transplantation. Another possible mechanism is poor antigen presentation by dendritic cells. This has been described in breast cancer and can be overcome by culturing patient dendritic cell precursors in granulocyte macrophage-colony-stimulating factor (GM-CSF) (56). Thus there are a variety of approaches to immune modulation that could be incorporated into future gene therapy experiments.

\section{MELANOMA VACCINES}

Work on melanoma vaccines supports the development of gene-modified tumor cell vaccines. Melanoma vaccines have been used in adjuvant therapy to prevent recurrence after surgery and to induce regression of metastases. For metastatic melanoma, the response rate to non-gene-modified tumor cell vaccines is about $10-15 \%$, mainly taking the form of partial remissions of several months' duration (57). This limited activity has been attributed to a large tumor burden, but it could equally be because of weak immunogenicity or evasion of host control. Melanoma vaccines reported in the 1970s and '80s included autologous tumor cells with various adjuvants such as BCG, CFA, or detoxified endotoxin plus BCG cell wall skeleton, as well as viral oncolysates of autologous or allogeneic tumor cells with Vaccinia or Newcastle disease virus (57). More recently, Berd et al. reported four complete and one partial remission in 40 patients treated with autologous irradiated tumor cells plus BCG, with one remission lasting $84^{+}$ months (58). This group also used haptenized autologous irradiated tumor cell vaccines with similar results (59). Mitchell and co-workers (60) reported one complete remission, two partial remissions, and three mixed responses in 25 patients treated with an allogeneic melanoma cell lysate plus Detox (detoxified endotoxin). Morton and co-workers have used a vaccine consisting of a mixture of three irradiated melanoma cell lines plus BCG to treat patients with stages III and IV disease rendered free of disease by surgery (61). Hersey used a Vaccinia viral oncolysate of three melanoma cell lines to treat patients after removal of positive lymph nodes (62). In both studies, significant prolongation of survival was noted in vaccine patients compared with historical controls. However, controlled clinical trials confirming these results have not been reported. Currently, there are three on-going randomized, controlled trials comparing $\alpha$-INF (the Federal Drug Administration [FDA]-approved adjuvant therapy) with vaccines. The current emphasis on melanoma vaccine research, exclusive of gene therapy approaches, is being carried out by the use of purified melanoma antigens, such as GM2 ganglioslide (63), or specific immunodominant peptides, such as those derived from the MAGE-1 MART-1/Melan A or gp-100 antigens (64). These have been shown to induce specific CTL responses in melanoma patients, but clinical benefit is not yet proven.

\section{ANIMAL MODELS}

In melanoma studies using animal models the major focus has been on gene-modified tumor cells as vaccines-either in the form of in vitro gene introduction followed by in vivo immunization (ex vivo-in vivo approach), or the direct in vivo introduction of genes into the tumor. Gene therapy of melanoma in animal models has been effective only for animals with recently inoculated tumor and a minimal tumor burden. The most frequent approach has been to vaccinate with syngeneic mouse melanoma cell lines that have been retrovirally transduced and selected via neomycin resistance to permanently express the gene of interest. These cells lack tumorogenicity compared with wild-type tumor when inoculated in vivo. The animals that reject the gene modified cells are resistant to subsequent challenge with wild-type tumor. This is due to the induction of CD8-positive CTL; treatment with anti-CD8 monoclonal antibody per- 
mits growth of the wild-type or gene-modified tumor. Vaccine administration after inoculation of wild-type tumor cells becomes less effective as the time from initial tumor inoculation to vaccination increases and is usually ineffective after 7 to 14 days between inoculation and vaccination. Anti-tumor immunity can also be overcome by increasing the dose of wild-type tumor cells on rechallenge. Thus, the tumor burden is a major factor in the by 1 - to 5 -fold efficacy of vaccine therapies.

Earlier work involving gene therapy of murine melanoma and other murine tumors has been summarized in a series of reviews published in 1994 and 1995 (65-70). More recent work is summarized below. This has tended to confirm and extend earlier observations without breaking much new ground. Almost all studies have been done in variants of B-16 melanoma, with emphasis on the highly metastatic clones. An important initial report by Dranoff et al. compared a spectrum of potential genes to augment tumor cell immunogenicity, including IL-2, -4, -5 , and -6, INF- $\gamma$, ICAM-1, TNF- $\alpha$, CD- 2 , and GM-CSF (71). Animals were vaccinated with either nonirradiated or irradiated retrovirally transduced tumor cells and challenged at 7 to 17 days with wild-type cells. In both instances, major slowing of tumor growth was achieved only by GM-CSF-transduced cells, with slight effects noted for IL-4 and IL-6. Vaccination with viable irradiated GM-CSF-secreting cells can induce CTL in the draining lymph nodes and these can be expanded in vitro with IL-2. When administered at $7 \times 10^{7}$, cells together with systemic IL-2, they decreased pulmonary metastases after IV inoculation of wild-type cells (72). Several studies have focused on the delivery of GM-CSF in Vaccinia virus constructs either by the intratumoral route (73), vaccination with irradiated Vaccinia-infected cells (74), or as a viral oncolysate (75). In each study, a wild-type tumor was established 3 to 10 days prior to a single vaccination. Decreased tumor growth and number of metastases and increased survival was noted, which correlated with the generation of CTL and of activated cytotoxic macrophages producing TNF- $\alpha$ and nitrous oxide. The immunological effect was specific and there was no effect in these animals on transplanted colon tumors. Similar results have been described for tumor cells retrovirally transduced with the IL-2 gene (76) or the B-7 gene and used as vaccines (77). One study suggested that vaccination with B-7-transduced cells acted only if the tumor was immu- nogenic (78). Animals were vaccinated with irradiated or nonirradiated B-7-transfected tumor cells, followed by wild-type challenge. Protection was seen for the RMA, E6B2, P815, and EL-4 tumors but not for MCA-101, MCA-102, AG104, or, interestingly, B-16 melanoma; the latter four were less immunogenic. Other gene delivery systems have also been effective, including intratumoral delivery of IL-2 plasmid DNA with the cationic lipid mixture DMRIE/DOPE. This greatly retarded tumor growth when applied 24 hr after subcutaneous tumor cell inoculation (79). When cells transfected with IL-2 in DMRIE/DOPE in vitro were given IV, they produced $75 \%$ less pulmonary metastases than those of wild-type cells, even though only the minority of cells was transfected. Particle-mediated gene delivery is also effective (80). Mice vaccinated with $1 \times 10^{6}$ irradiated B-16 melanoma cells secreting greater than $100 \mathrm{ng} / \mathrm{ml} / 10^{6}$ cells of GM-CSF after transfection by bombardment with plasmid DNA on gold particles with gene gun showed $60 \%$ survival versus $5 \%$ survival for animals vaccinated with control cells. Efficacy was seen against a challenge of $1 \times 10^{5}$ and $1 \times 10^{6}$ wild-type cells but not at $5 \times 10^{6}$ cells. Intratumoral injection of naked DNA can also effectively transfer a marker gene into tumors (81). These studies also suggest that transient expression of the transgene may be sufficient for effective vaccine therapy.

A number of investigators have studied the transfer of genes via the administration of syngeneic, allogeneic, or xenogeneic carrier cells. In one study, allogeneic fibroblasts were cotransfected with B-16 MAA and IL-2. (82). Vaccination followed by wild-type tumor cell challenge resulted in $40 \%$ long-term survival, compared with $20 \%$ survival in animals vaccinated with constructs not expressing IL-2 and $0 \%$ survival in untreated controls. This approach has also been effective in treating animals with established tumor (83). An intriguing study in spontaneous canine melanoma utilized xenogeneic Vero cells stably transformed to produce IL- 2 and injected intratumorally at $3 \times 10^{7}$ cells weekly following surgery and radiotherapy (84). Compared with controls, there were $0 / 16$ versus $6 / 16$ late recurrences and $40 \%$ versus $5 \%$ long-term survival.

The hypothesis that combining two genes (that correct or augment different components of tumor immunity) may be more effective than one is also being tested. Combinations reported to show augmented therapeutic efficacy in mu- 
rine models include IL-4 plus IL-2 (85), B-7 plus IL-12 (protein or gene) (86), and IFN- $\gamma$ plus IL-2 (87). In animals with 3-day established pulmonary metastasis of B-16 melanoma, weekly intraperitoneal i.p. injection of $2 \times 10^{6}$ inactivated B-16 cells secreting both IL-2 and IL- 6 had $60 \%$ survival at 90 days compared with $10 \%$ and $30 \%$ for the two genes administered alone and $0 \%$ for untreated controls (88).

Other recent approaches to gene therapy of melanoma include transfection with MHC class I genes to restore $\mathrm{MHC}$ expression and reduce metastatic potential (89), and gene transfer of TIMP-1 (tissue inhibitor of metalloproteinase), which showed reduced subcutaneous growth and reduced lung metastases after IV injection in B16 melanoma (90). Intracerebral implants of the human melanoma line SK Mel-2 in nude rats show marked tumor volume reduction from 72 to $1.2 \mathrm{~mm}^{3}$ when the cells were transduced to express vascular endothelial growth factor (VEGF) antisense (91). Intratumoral injection of the $\mathrm{H}$-ras ribozyme in an adenoviral vector resulted in dose-dependent complete regression of established subcutaneous nodules of the human FEM melanoma growing in nude mice (92). Thus, the options for gene therapy of melanoma are extensive. The challenge is to translate these observations into meaningful clinical experiments and effective therapy.

\section{IN VITRO STUDIES OF GENE TRANSFER IN HUMAN CELLS}

In most instances, the initial trials of gene therapy have been based not only on animal model studies but also on in vitro studies of gene transfer to human melanoma cells and carrier cells. Approaches utilized include retrovirus-mediated transfer with selection via neomycin resistance, adenovirus vectors, cationic lipid-mediated plasmid DNA transfer, particle-mediated transfer with the gene gun, and electroporation. Genes transferred to human melanoma cells include the cytokines IL-2, IL-4, IL-7, IL-12, INF- $\gamma$, and GM-CSF; the neomycin resistance gene; $\beta$-galactosidase; luciferase; the costimulatory molecule B7.1; HLA-A2, HLA-B7/ $\beta 2 M$, and other MHC class I genes; and the melanoma-associated antigens MART-1 and gp-100. Treated cells include autologous and allogeneic fresh and cultured melanoma cell lines, carrier cells, and antigenpresenting dendritic cells. These studies have ad- dressed the mechanics of gene transfer, including transfection or transduction efficiency, level and duration of expression, and biological activity and gene expression after freezing, thawing, and irradiation.

Using retroviral transfection followed by selection for the transgene, stable lines with $100 \%$ expression can be established from fresh tumor cells. However, up to 100 days may be required to establish lines in $30 \%$ to $90 \%$ of attempts. In one study, 78 tissue specimens were obtained, 68 fibroblast lines were established, and 21 of these cell lines were successfully transduced to express greater than 1000 units of IL-4 for at least 3 weeks (93). With adenovirus transduction, cell lines need not be established and 50\% to $100 \%$ of human cell lines and fresh tumor cells are transduced and express the gene for 7 to 30 days in vitro at multiplicity of infection rates (MOIs) of 10 to 300 . In one study, at an MOI of 10 to 20, B7.1 was successfully transferred to and expressed in $20 \%$ to $94 \%$ of the fresh melanoma cells (94). In our program, at an MOI of 33 to $300,100 \%$ of fresh or early-passage melanoma cells expressed $\beta$-galactosidase for up to 30 days (95). Human dendritic cells are readily transduced with a variety of genes, including luciferase, $\beta$-galactosidase, IL-2, or IL-7 at an efficiency of greater than $95 \%$ at the higher MOIs (96). This has also been accomplished with retrovirus vectors (97). Physical or physicochemical methods of in vitro gene transfer are also effective. We have studied delivery of plasmid DNA containing the IL-2 gene under the control of the cytomegalovirus (CMV) promoter via the cationic lipid complex DMRIE/DOPE in fresh melanoma cells and cell lines (98). Transfection of established cell lines with these DNA-lipid complexes (lipoplexes) yielded 10 to 100 times more IL-2 production (1000 to $10,000 \mathrm{IU} / 10^{6}$ cells $/ 24$ hr) than did fresh tumor cells. IL-2 expression was seen in all melanoma cells for 2 to 4 weeks. IL-2 was active, as measured by the ability of culture supernatants to stimulate lymphocyte proliferation and LAK cell generation. Cationic lipids or other polycationic substances such as polybrene and protamine also promote more efficient adenovirus transduction of human tumors in vitro (99). $\beta$-galactosidase expression was increased 2- to 10-fold in UM449 melanoma cells by the concurrent application of cationic lipid and adenovirus.

Particle-mediated gene transfer was also reasonably efficient in vitro, although gene expression lasted only 7 to 14 days. Transfer of INF- $\gamma$ 
into early-passage melanoma cell lines yielded 50 to $5000 \mathrm{pg} / 10^{6}$ cells $/ \mathrm{ml}$ of INF- $\gamma(100)$. With particle-mediated transfer of B7.1, $8 \%$ to $31 \%$ of cells expressed the gene product. Multiple gene delivery is easily accomplished with $9 \%$ to $33 \%$ of the cells expressing HLA-DR and B7.1 (100) and $10-17 \%$ of cells expressing HLA-A2 plus B7.1 (100) in two studies. Transfer of tumor antigens to antigen-presenting Cos cells, B cells, or dendritic cells has also been accomplished for MHC class I, MART-1, and gp-100 (101).

These transformed cells are active immunologically. Cells secreting IL-2 induce lymphocyte proliferation and generate both LAK cells and CTL (102). They generate MHC-restricted CTL more efficiently than wild-type cells in vitro (103). IL-7 transformed cells show increased sensitivity to lysis by cytokine-induced killer (CIK) cells (104). For retrovirus-transformed and -selected TIL, the introduction of the neo-R or TNF- $\alpha$ genes did not impair their function (105). B cells transformed with both MHC-l and tumor antigen (MART-1 or gp-100) induced antigenspecific CTL (101) (proving the carrier concept) and dendritic cells transformed with gp-100 induced patient lymphocytes to produce INF- $\gamma$ in vitro (106). Thus, there is ample evidence that efficient in vitro gene transfer to human cells can be accomplished with one, two, or even three genes and that the transformed cells evoke the desired immunologic function.

\section{CLINICAL TRIALS}

Assuming that effective strategies for gene therapy of cancer will be developed, their application to melanoma will start in the prevention mode. High-risk patients, including those with prior primary melanomas, a strong family history, the dysplastic nevus syndrome, or germ-line tumor suppressor gene mutations and deletions could be vaccinated with transformed cells, naked DNA, or viral vectors containing prevalent MAAs. Similarly, patients at high risk for recurrence after excision of primary tumor or metastatic tumor could also receive vaccines. Currently, since gene therapy is in an early stage of development, only treatment of patients with metastatic disease is justified. The development of gene therapy for melanoma is preceding through animal model studies, in vitro studies using human cells, and clinical trials in advanced disease. As progress is made, gene therapy will be investigated during earlier stages of disease, in the adjuvant setting, and eventually, as prevention. The strongest rationale for gene therapy of melanoma is the use of gene-modified tumor cells or recombinant viral immunogens for active immunotherapy; this is the only approach that does not require delivery of the gene to every tumor cell-a goal we have not yet achieved. Since the newer approaches to chemo- and biotherapy of melanoma have substantially improved remission rates, reduction of tumor burden can also be carried out prior to gene therapy. Approaches proposed for gene therapy of melanoma include (1) replacement of a missing or mutated gene (such as the P16 tumor-suppressor gene), (2) introduction of a gene that activates a prodrug within the tumor (such as HSV-TK for gancyclovir), (3) introduction of antisense or ribozyme to inactivate an oncogene product (such as h-ras) or other detrimental tumor cell products (such as TGF- $\beta$ ), and (4) introduction of a gene to increase the immunogenicity of the tumor cells (such as B7.1 or allogeneic MHC class I). To date, most studies of melanoma in both animal models and humans have focused on active immunotherapy with gene-modified tumor cells or viral constructs expressing genes for immunogenic antigens because melanoma is immunogenic, is under host immune control, and responds to conventional tumor vaccines to a limited extent, and because immunization does not require us to deliver genes to all tumor cells. This is the current approach of choice.

Clinical trials of gene therapy fall into several broad categories, including cytokine gene therapy, administration of allogeneic histocompatibility antigen genes, gene marking studies, and administration of the HSV-TK gene followed by gancyclovir and DNA vaccines. Results have mainly been reported at scientific meetings and specialized conferences as abstracts; few results have been reported in peer-reviewed journals. Most studies are phase I or feasibility studies involving less than 25 patients with far-advanced, drug-resistant, metastatic disease. However, most of these studies have demonstrated some biological activity with limited numbers of responses and little data on response duration or survival. No studies are reported comparing the efficacy of gene-modified tumor cell vaccines with conventional tumor cell vaccines. The strategy is to complete pilot and phase I studies and then to conduct studies with patients with a minimal tumor burden because it is unlikely that major anti-tumor effects will be seen in patients with a large volume of metastatic disease. A July 
1996 compendium of clinical trials reported 39 active protocol with 20 distinct approaches in melanoma (107). In a June 1997 update of melanoma gene therapy trials there were 11 cytokine immunotherapy trials for advanced cancer including melanoma, 19 cytokine immunotherapy trials specifically for melanoma, 3 lymphocyte transfer studies, and two HSV-TK/gancyclovir trials (108). There were no clinical trials using drug-resistant genes or oncogenes, or tumorsuppressor gene modification. The TMC Development World-Wide Therapy Enrollment Report from December 1996 reported 37 melanoma trials involving 466 patients with 13 different genes (109). Certainly, this level of effort should result in a substantial body of data within the next 2 years.

The first human cancer gene transfer trial reported by Rosenberg and co-workers utilized TIL cells from melanoma metastases expanded in vitro with IL-2, retrovirally transfected with the neo-R or TNF- $\alpha$ genes, and reinfused with systemic high-dose IL-2. Persistence of the transduced TIL was detected by polymerase chain reaction (PCR) in blood and tumor tissue (110). Five patients received up to $2 \times 10^{11}$ marked cells (1-11\% expressing the neo-R gene). There were no side effects and circulating cells were detected for up to 6 months. Three patients had regression of at least one tumor nodule, which is consistent with prior results for unmodified TIL therapy. The study was updated in 1993, reporting 10 patients with the same result (111). Additional similar studies have been reported (112). In one study, gene-marked cells were detected in tumor nodules of $4 / 8$ patients up to 260 days after four $92 \times 10^{9}$ gene-marked cells containing $1-26 \%$ positive cells were transfused (113). The question still remains as to whether these cells, which may secrete up to 100 times the usual level of cytokine such as TNF, will mediate a more effective therapeutic response than unmodified TIL cells. Multiple studies have also been done or are under way in the bone marrow transplant setting to explore the distribution and fate of gene-marked stem cells $(114,115)$.

Tumor vaccines with cells modified to secrete immunomodulatory cytokines have received the greatest attention clinically. Several studies have used autologous irradiated tumor cells modified in vitro to secrete GM-CSF. In one study, 24 patients received three doses of $5 \times 10^{6}$ or $5 \times 10^{7}$ autologous, irradiated, retrovirally transformed tumor cells every 21 days for three doses (116). Toxicity was limited to local eryth- ema and edema at the injection site. All patients developed delayed hypersensitivity to skin tests with unmodified tumor cells after the third injection. No tumor regressions were noted, but five patients had stable disease. The median survival at the $5 \times 10^{6}$ cell dose was 16 months and was not reached at $5 \times 10^{7}$ cells, suggesting a possible dose response. In another study, patients were vaccinated with autologous irradiated tumor cells secreting GM-CSF at greater than $40 \mathrm{ng} / 10^{6}$ cells $/ 24 \mathrm{hr}$ (117). Tumor responses were not mentioned, but 16 out of 25 patients were alive at 4-22 months. There were increasing local reactions at up to 12 injections. CTL reacting to autologous tumor were isolated from the injection sites of several patients.

Autologous irradiated tumor cells retrovirally transduced with IFN- $\gamma$ have also been studied (118). In one report, 58 melanoma patients were entered, twelve tumor lines were established, and five of these were successfully retrovirally transduced and used as a vaccine at $2 \times$ $10^{7}$ cells every 2 weeks for six doses. No responses were seen, but most patients developed anti-tumor antibodies. Another group treated 20 melanoma patients with autologous irradiated tumor cells secreting INF- $\gamma$ every 2 weeks for 3 months with doses escalating from two $18 \times 10^{6}$ cells (119). The transduced cells showed increased expression of HLA class I, II, and ICAM-1. In vitro stimulation of patient lymphocytes with these cells produced lytic CTL and NK cells, and release of THl cytokines. Eight of 13 patients tested developed anti-melanoma antibodies and 2 of 20 had complete tumor regression.

Autologous gene-modified fibroblasts have also been used to deliver cytokines intratumorally. In one study, retrovirally transformed autologous fibroblasts secreting 10 to $300 \mathrm{ng} / 10^{6}$ cells $/ 24 \mathrm{hr}$ of IL-12 were given intratumorally weekly for four doses (120). Three of seven melanoma patients showed partial remission. In another study, the autologous fibroblasts transduced to produce IL-4 were injected intratumorally (121). Biopsy at 14 days showed both IL-4 and Neo-R mRNA proving in vivo gene expression. No therapeutic data were reported.

Another approach has been to use genemodified MHC class I-matched allogeneic melanoma cell lines as vaccines. Since these cells present melanoma-associated antigens in the context of self MHC, they overcome the need for removal and in vitro transformation of the patient's tumor cells. In one study, patients re- 
ceived four injections of 10 to $50 \times 10^{6}$ cells producing $40 \mathrm{IU}$ of IL-2/10 $0^{6}$ cells/24 hr (122). One of 12 stage IV patients remitted and was alive and symptom-free at 25 months. Another group used allogeneic irradiated HLA-Al or A2 melanoma cells secreting $0.1 \mathrm{mcg}$ of $\mathrm{IL}-2 / 10^{6}$ cells $/ 24 \mathrm{hr}$ given weekly for three doses (123). Five of 24 patients with metastatic disease showed regression of metastatic nodules. There was an increase in circulating CTL in these patients. Another group observed three mixed responses in 12 HLA-A2-positive patients with HLA-A2 melanoma cell lines modified to secrete IL-2 with 5 or $15 \times 10^{7}$ cells on Days $1,13,26$, and 55 (124). In a minority of patients, increased recognition of MAA by CTL precursors was observed. Viruses have also been used to directly transfer genes to tumors in vivo. One study showed that the Vaccinia E3L gene product was still expressed in tumors 2 months after intratumoral vaccination (125). One of five patients had a local response. In another study, Vaccinia GMCSF construct was injected intratumorally at $10^{4}$ to $10^{7}$ PFU twice weekly for 12 to 15 weeks (126). One of three patients had a partial remission, including regression of noninjected metastases. A retroviral construct expressing the INF- $\gamma$ gene has also been used by direct intratumoral injection in melanoma (127). The dose was $1.5 \times$ $10^{8} \mathrm{CFU}$ over 5 days into one nodule in three patients (127). One showed successful gene transfer.

Another approach to melanoma gene therapy is the use of plasmid DNA complexed with the cationic lipid complex DMRIE/DOPE (128). In the initial clinical study, five HLA-B7 negative patients were treated with multiple intratumoral injections of less than $1 \mathrm{mcg}$ of HLA-B7 DNA complexed with DMRIE/DOPE (129). Gene transfer and expression was documented in biopsies from of all five patients. Anti-tumor CTL developed in the two patients tested and $1 / 5$ had a substantial partial remission. This group subsequently treated an additional 10 patients (130). There was one local response in an injected nodule and one partial remission including uninjected metastases. The transferred gene was detected in 9 of 10 patients. Increased TIL were observed in six of seven postinjection biopsies. Specific CTL were obtained from tumor biopsies in 2 of 2 patients. Subsequent administration of in vitro-expanded CTL from the injected nodule of one of these biopsies induced a complete remission. These investigators also showed an increase in TCR-V $\beta$ gene family diversity in both injected and noninjected lesions, which suggests that a systemic immune effect occurred after treatment (131).

Our group initiated a formal phase I study of HLA-B7/B2M/DMRIE/DOPE intratumoral gene therapy in HLA-B7-negative, stage IV melanoma patients (132). One to three doses at 2- to 4week intervals of 10,50 , or $250 \mathrm{mcg}$ of DNA were given intratumorally into a single tumor nodule. Toxicities were limited to mechanical effects of needle placement and included local hemorrhage, pain, and minimal pneumothorax in two patients with lung nodules. Regression of injected nodules greater than $25 \%$ was observed in 7 of 14 evaluable patients. One patient with a single site of retroperitoneal disease had a complete remission after three doses. The median survival of the total group was 8.1 months. Concurrent phase I studies were done with 14 patients with metastatic colon cancer (133) and 15 patients with metastatic renal cell carcinoma (134) using an identical experimental design. No esponses were noted in these two studies. In all three phase I studies, greater than $80 \%$ of patients had plasmid DNA detected in post-treatment biopsies up to 8 weeks after one dose. Over $80 \%$ of patients also had HLA-B7 protein detected by immunohistochemistry or flow cytometry, and $\mathrm{CD}-8$-positive $\mathrm{T}$ cells infiltrating the tumor were noted post-treatment in about $80 \%$ of patients. About $40 \%$ of patients developed peripheral blood lymphocytes reactive to HLA-B7 $(135,136)$.

In another study, seven patients with metastatic malignant melanoma (three of whom were HLA-B7 positive but whose tumors did not express HLA-B7) were treated intratumorally with 10 mcg of HLA-B7 DNA in DMRIE/DOPE (137). There were three responses, including two partial remissions, both in patients who were HLA-B7 positive. This suggests that restoration of HLA class I expression can induce anti-tumor immune responses. In these four phase I studies in melanoma a total of 36 patients were treated (138). Thirty-six percent had a regression of the injected nodule and $19 \%$ had regression of disease at distant noninjected sites, which suggests the induction of generalized tumor immunity. Another group conducted a phase I study of 10 , 20, or 50 mcg of HLA-B7 DNA in DMRIE/DOPE injected intratumorally every 2 weeks in patients who had a variety of malignancies including melanoma, head and neck cancer, and nonsmall-cell lung cancer (139). One partial remission and one mixed response were noted in the 
two patients with lung cancer. HLA-B7, plasmid DNA complexed with DMRIE/DOPE was also delivered by the intra-arterial route to a lung nodule that expressed HLA-B7 DNA and protein (140). On the basis of these data, phase II studies of HLA-B7 DNA intratumoral gene therapy are now being conducted in patients with different tumor types.

We have also conducted a phase I study of intratumoral injection plasmid DNA encoding the IL-2 gene complexed with DMRIE/DOPE in patients with various malignancies (141) on the basis of animal studies and data from our laboratory, showing efficient gene transfer to both fresh and cultured tumor cells. Doses of 10, 30, 100 , and 300 mcg of DNA were given to cohorts of five to nine patients with metastatic malignancy weekly for six doses into the same nodule. DNA was detected in $75 \%$ of the patients, $\mathrm{T}$ cell infiltration in $50 \%$ of patients, and IL-2 protein in $60 \%$ of patients. Five of 23 evaluable patients had regression of the injected nodule. There was no regression of noninjected lesions.

\section{DISCUSSION}

These studies of in vitro and in vivo gene transfer and gene therapy illustrate the promise and limitations of the currently available technology. The reader should remember that the basis for these approaches is that immunization with gene-modified tumor cells is superior to unmodified cells in the animal models; this remains unproven in humans. Successful gene transfer, biological activity, stimulation of immune reactivity, and limited clinical responses have been observed in patients with advanced, refractory, chemotherapy-resistant disease-a circumstance in which the animal studies would have predicted failure. There have been almost no clinical and very limited preclinical studies defining optimal cell dose, level of cytokine secretion, treatment schedule, and duration. Clearly, more rational and quantitative designs are needed to determine whether this approach can be successful enough to result in licensing of these agents. The current data reinforce the recent recommendations in the Report and Recommendations of the Panel to Assess the NIH Investment in Research on Gene Therapy (142). These included the following: (1) focusing on basic aspects of gene transfer; (2) improving vectors for gene delivery for enhancing and maintaining high levels of expression, tissue specificity of expression, and regulated expression, and developing vectors for targeted delivery; (3) developing relevant preclinical models; and (4) maintaining high standards of experimental design for clinical protocols.

What should our immediate goals and strategies be for the development of gene therapy, beyond those recommended by the NIH panel? For the current technology, reasonable animal models have been established. These studies should be focused on (1) comparative studies to determine the most efficient vector for intratumoral gene delivery; (2) better definition of the dose, schedule, and duration of intratumoral gene treatment; (3) better definition of the dose schedule and duration of treatment with genemodified tumor cell vaccines; (4) testing limits of tumor burden on efficacy of gene delivery in the setting of established tumor; (5) further exploration of combinations of genes; (6) exploration of combining gene therapy with strategies designed to overcome evasion of host control; and (7) further development of DNA vaccines. For clinical applications we must develop a gene therapy product that can be widely used and manufactured as a conventional pharmaceutical. Thus, for tumor cell vaccines, autologous tumor cells or fibroblasts, while experimentally interesting, are not practical. Established tumor cell lines expressing specific MHC and tumor antigen and gene product could be FDA approved and marketed. DNA vaccines should also be explored for this reason. We must define the optimal cytokine secretion level, cell dose, dose schedule, and treatment duration for these cellular vaccines. Treatment must be moved into patients with earlier-stage disease with limited tumor burdens or into the adjuvant setting. Trials should begin with combinations of two genes and with additional strategies to overcome evasion of host control. There is reason for optimism that these additional strategies, which are all technically feasible today, will substantially improve the clinical efficacy of gene therapy.

\section{REFERENCES}

1. Parker SL, Tong T, Bolden S, et al. (1997) Cancer statistics, 1997. CA Cancer J. Clin. 47: 5-27.

2. Thorn M, Adami HA, Bergstrom R, et al. (1989) Trends in survival from malignant melanoma: Remarkable improvement in 23 years. J. Natl. Cancer Inst. 81: 611-618. 
3. Balch CM, Soong S, Shaw HM, et al. (1992) An analysis of prognostic factors in 8500 patients with cutaneous melanoma. In: Balch CM, Houghton AN, Milton GW, et al. (eds). Cutaneous Melanoma. J.B. Lippincott, New York, pp. 165-187.

4. Bakker ABH, Marland G, deBoer AJ, et al. (1995) Generation of antimelanoma cytotoxic $\mathrm{T}$ lymphocytes from healthy donors after presentation of melanoma-associated antigen-derived epitopes by dendritic cells in vitro. Cancer Res. 55: 5330-5334.

5. Kawakami Y, Robbins PF. (1995) Genes coding for tumor antigens recognized by $\mathrm{T}$ lymphocytes. In: DeVita VT, Jr., Hellman S, Rosenberg SA (eds). Biologic Therapy of Cancer. J. B. Lippincott, Philadelphia, pp. 5364.

6. Aebersold P, Hyatt C, Johnson S, et al. (1991) Lysis of autologous melanoma cells by tumor-infiltrating lymphocytes: Association with clinical response. J. Natl. Cancer Inst. 83: 932-937.

7. Albino AP, Lloyd KO, Houghton AN, et al. (1981) Heterogeneity in surface antigens and glycoprotein expression of cell lines derived from different melanoma metastases of the same patient. J. Exp. Med. 154: 17641778.

8. Shiku H, Takahashi T, Oettgen HF, et al. (1976) Cell surface antigens of human malignant melanoma. J. Exp. Med. 144: 873881.

9. Shiku H, Takahashi T, Resnick LA, et al. (1977) Cell surface antigens of human malignant melanoma. J. Exp. Med. 145: 784789.

10. Houghton AN. (1994) Cancer antigens: Immune recognition of self and altered self. $J$. Exp. Med. 180: 1-4.

11. Houghton AN, Brooks $\mathrm{H}$, Cote RJ, et al. (1983) Detection of cell surface and intracellular antigens by human monoclonal antibodies. J. Exp. Med. 158: 53-65.

12. van der Bruggen $P$, Traversari $C$, Chomez $P$, et al. (1991) A gene encoding an antigen recognized by cytologic $\mathrm{T}$ lymphocytes on a human melanoma. Science 254: 1643-1647.

13. Rosenberg SA. (1996) Development of cancer immunotherapies based on identification of the genes encoding cancer regression antigens. J. Natl. Cancer Inst. 88: 1635-1644.

14. Carrel S, Rimoldi D. (1993) Melanoma-associated antigens. Eur. J. Cancer 29A: 19031907.
15. Brichard V, Van Pel A, Wolfel T, et al. (1993) The tyrosinase gene codes for an antigen recognized by autologous cytolytic $\mathrm{T}$ lymphocytes on HLA-A2 melanomas. $J$. Exp. Med. 178: 489-495.

16. Robbins PF, El-Gamil M, Kawakami Y, Stevens E, Yanelli JR, Rosenberg SA. (1994) Recognition of tyrosinase by tumorinfiltrating lymphocytes from a patient responding to immunotherapy [published erratum in Cancer Res (1994) 54: 3952]. Cancer Res. 54: 3124-3126.

17. Wolfgang JR, Real FX, Spengler BA, et al. (1986) Human melanoma proteoglycan: Expression in hybrids controlled by intrinsic and extrinsic signals. Science 231: 12811284.

18. Carrel S, Dore J-F, Ruiter DJ, et al. (1991) The EORTC melanoma group exchange program: Evaluation of a multicenter monoclonal antibody study. Int. J. Cancer 48: $836-847$.

19. Reisfeld RA (1993) International Consensus Conferences on Human Melanoma Antigens. Meeting Report. Melanoma Res. 3: 209-217.

20. Real FX, Mattes MJ, Houghton AN, Oettgen HF, Lloyd KO, Old LJ. (1984) Class I (unique) tumor antigens of human melanoma. Identification of a 90,000 dalton cell surface glycoprotein by autologous antibody. J. Exp. Med. 160: 1219.

21. Cheresh DA. (1991) Structure, function, and biological properties of integrin $\alpha_{v} \beta_{3}$ on human melanoma cells. Cancer Metastasis Rev. 10: 3-10.

22. Luca M, Hunt B, Bucana CD, Johnson JP, Fidler IF, Bar-Eli M. (1993) Direct correlation between MUC1 8 expression and metastatic potential of human melanoma cells. Melanoma Res. 3: 35-41.

23. Hom SS, Topalian SL, Simonis $\mathrm{T}$, et al. (1991) Common expression of melanoma tumor-associated antigens recognized by human tumor infiltrating lymphocytes: Analysis by human lymphocyte antigen restriction. J. Immunother. 10: 153-164.

24. Gaugler B, Van den Eynde B, van der Bruggen $P$, et al. (1994) Human gene MAGE-3 codes for an antigen recognized on a melanoma by autologous cytolytic $\mathrm{T}$ lymphocytes. J. Exp. Med. 179: 921-930.

25. Li J, Yang Y, Fujie T, et al. (1996) Expression of BAGE, GAGE, and MAGE genes in 
human gastric carcinoma. Clin. Cancer Res. 2: 1619-1625.

26. Bakker ABH, Schreurs MWJ, de Boer AJ, et al. (1994) Melanocyte lineage-specific antigen gpl00 is recognized by melanoma-derived tumor-infiltrating lymphocytes. $J$. Exp. Med. 179: 1005-1009.

27. Kawakami Y, Eliyahu S, Delgado $\mathrm{CH}$, et al. (1994) Cloning of the gene coding for a shared human melanoma antigen recognized by autologous $\mathrm{T}$ cells infiltrating into tumor. Proc. Natl. Acad. Sci. USA 91: 35153519.

28. Kawakami Y, Robbins PF, Wang RF, et al. (1996) Identification of melanoma antigens recognized by $\mathrm{T}$ lymphocytes and their use in the immunotherapy of cancer. Princ. Practices of Oncol. 10: 1-20.

29. Cox AL, Skipper J, Chen Y, et al. (1994) Identification of a peptide recognized by five melanoma-specific human cytotoxic $T$ cell lines. Science 264: 716-720.

30. Rosenberg, SA. (1995) The development of new cancer therapies based on the molecular identification of cancer regression antigens. Cancer J. Sci. Am. 1: 90-100.

31. van Duinen SG, Ruiter DJ, Broecker EB, et al. (1988) Level of HLA antigens in locoregional metastases and clinical course of the disease in patients with melanoma. Cancer Res. 48: 1019-1025.

32. Weber JS, Rosenberg SA. (1990) Effects of murine tumor class I major histocompatibility complex expression on antitumor activity of tumor-infiltrating lymphocytes. J. Natl. Cancer Inst. 82: 755-761.

33. Weber JS, Rosenberg SA. (1988) Modulation of murine tumor major histocompatibility antigens by cytokines in vivo and in vitro. Cancer Res. 48: 5818-5824.

34. Guinan EC, Gribben JG, Boussiotis VA, et al. (1994) Pivotal role of the B7: CD 28 pathway in transplantation tolerance and tumor immunity. Blood 84: 3261-3282.

35. Howard M, O'Garra A. (1992) Biological properties of interleukin 10. Immunol. Today 13: 198-200.

36. Fuchs AC, Granowitz EV, Shapiro L, et al. (1996) Clinical, hematologic, and immunologic effects of interleukin-10 in humans. J. Clin. Immunol. 16: 291-304.

37. Sato T, McKue P, Kazuhiro M, et al. (1996) Interleukin 10 production by human melanoma. Clin. Cancer Res. 2: 1383-1390.

38. Massague J. (1990) The transforming growth factor- $\beta$ family. Annu. Rev. Cell Biol. 6: $597-641$.

39. Park JA, Kurt RA, Wang E, Schluter SF, Hersh EM, Akporiaye ET. (1997) Expression of an antisense TGF- $\beta 1$ transgene reduces tumorigenicity of EMT 6 mammary tumor cells. Cancer Gene Ther. 4: 42-50.

40. Sage EH. (1997) Terms of attachment: SPARC and tumorigenesis. Nature Med. 3: 144-146.

41. Ledda MF, Adris S, Bravo AI, et al. (1997) Suppression of SPARC expression by antisense RNA abrogates the tumorigenicity of human melanoma cells. Nature Med. 3: 171-176.

42. Nagata S, Goldstein P. (1995) The Fas death factor. Science 267: 1449-1456.

43. Apasov S, Redegeld F, Sitkovsky M. (1993) Cell-mediated cytotoxicity: Contact and secreted factors. Curr. Opin. Immunol. 5: 404410.

44. Chong ASF, Scuderi P, Grimes WJ, and Hersh EM. (1989) Tumor targets stimulate IL-2 activated killer cells to produce interferon- $\gamma$ and tumor necrosis factor. J. Immunol. 142: 2133-2139.

45. Strand S, Hofmann WJ, Hug H, et al. (1996) Lymphocyte apoptosis induced by CD95 (APO-1/Fas) ligand-expressingtumorcellsA mechanism of immune evasion? Nature Med. 2: 1361-1366.

46. Seino K-I, Kayagaki N, Okumura K, et al. (1997) Antitumor effect of locally produced CD95 ligand. Nature Med. 3: 165-170.

47. Hahne M, Rimoldi D, Schroter $M$, et al. (1996) Melanoma cell expression of Fas (Apo-1/CD95) ligand: Implications for tumor immune escape. Science 274: 13631366.

48. Galle PR, Hoffman WJ, Walczak H (1995) Involvement of the CD95 (APO-1/Fas) receptor and ligand in liver damage. J. Exp. Med. 182: 1223-1230.

49. Dean M, et al. (1996) Genetic restriction of HIV-1 infection and progression to AIDS by a deletion allele of the CCR5 structural gene. Science 273: 1856-1862.

50. Nagata S. (1996) Fas ligand and immune evasion. Nature Med. 2: 1306-1307.

51. Griffith T, Brunner T, Fletcher S, Green D, Ferguson T. (1995) Fas ligand-induced apoptosis as a mechanism of immune privilege. Science 270: 1189-1192.

52. Gimmi CD, Morrison BW, Mainprice BA, et al. (1996) Breast cancer-associated antigen, 
DF3/MUCl, induces apoptosis of activated human T cells. Nature Med. 2: 1367-1370.

53. Hahne M, Rimddi D, Schroter M (1996) Melanoma cell expression of Fas(Apo-1/ CD95) ligand: Implications for tumor immune escape. Science 274: 1363-1366.

54. Kono K, Ressing M, Brandt RMP, et al. (1996) Decreased expression of signaltransducing $\zeta$ chain in peripheral $\mathrm{T}$ cells and natural killer cells in patients with cervical cancer. Clin. Cancer Res. 2: 1825-1828.

55. Zea AH, Curti BD, Longo CD, Alvord WG, Srobl SL, Mizoguchi H, Creekmore SP, O'Shea JJ, Powers GC, Urba WJ, Ochoa AC. (1995) Alterations in T cell receptor and signal transduction molecules in melanoma patients. Clin. Cancer Res. 1: 1327-1335.

56. Gabrilovich DI, Corak J, Ciernik IF, et al. (1997) Decreased antigen presentation by dendritic cells in patients with breast cancer. Clin. Cancer Res. 3: 483-490.

57. Mastrangelo MJ, Schultz S, Kane M, et al. (1988) Newer immunologic approaches to the treatment of patients with melanoma. Semin. Oncol. 15: 589-594.

58. Berd D, Maguire $\mathrm{H}, \mathrm{Jr}$, McCue $\mathrm{P}$, et al. (1990) Treatment of metastatic melanoma with an autologous tumor-cell vaccine: Clinical and immunologic results in $64 \mathrm{pa}-$ tients. J. Clin. Oncol. 8: 1858-1867.

59. Berd D, Murphy G, Maguire H, Jr, Mastrangelo MJ. (1991) Immunization with haptenized, autologous tumor cells induces inflammation of human melanoma metastases. Cancer Res. 51: 2731.

60. Mitchell MS, Harel W, Kempf R, et al. (1990) Active-specific immunotherapy for melanoma. J. Clin. Oncol. 8: 856-869.

61. Morton DL, Foshag LJ, Hoon DSB, et al. (1992) Prolongation of survival in metastatic melanoma after active specific immunotherapy with a new polyvalent melanoma vaccine. Ann. Surg. 216: 463-482.

62. Hersey P. (1992) Active immunotherapy with viral lysates of micrometastases following surgical removal of high risk melanoma. World J. Surg. 16: 251-260.

63. Livingston PO, Natoli EJ, Calves MJ, et al. (1987) Vaccines containing purified GM2 ganglioside elicit GM2 antibodies in melanoma patients. Proc. Natl. Acad. Sci. USA 84: 2911-2915.

64. Cormier JM, Sallgaller ML, Prevette T, et al. (1997) Enhancement of cellular immunity in melanoma patients immunized with a peptide from MART-1/melan A. Cancer J. 3: 37-44.

65. Fujiwara T, Grimm EA, Roth JA. (1994) Gene therapeutics and gene therapy for cancer. Curr. Opin. Oncol. 6: 96-105.

66. Porgador A, Feldman M, Eisenbach L. (1994) Immunotherapy of tumor metastasis via gene therapy. Natl. Immunol. 13: 113-130.

67. Goldfarb RH, Whiteside TL, Basse PH, et al. (1994) Natural killer cells and gene therapy: Potential of gene transfection for optimizing effector cell functions and for targeting gene products into tumor metastases. Nat. Immun. 13: 131-140.

68. Uckert W, Walther W. (1994) Retrovirusmediated gene transfer in cancer therapy. Pharmacol. Ther. 63: 323-347.

69. Miller AR, McBride WH, Hunt $\mathrm{K}$, et al. (1994) Cytokine mediated gene therapy for cancer. Ann. Surg. Oncol. 1: 436-450.

70. Ettinghausen S, Rosenberg SA. (1995) Immunotherapy and gene therapy of cancer. Adv. Surg. 8: 223-254.

71. Dranoff G, Jaffee E, Lazenby A, et al. (1993) Vaccination with irradiated tumor cells engineered to secrete murine granulocyte-macrophage colony-stimulating factor stimulates potent, specific, and long-lasting anti-tumor immunity. Proc. Natl. Acad. Sci. USA 90: 35393543.

72. Arca MJ, Krauss JC, Aruga A, et al. (1996) Therapeutic efficacy of $\mathrm{T}$ cells derived from lymph nodes draining a poorly immunogenic tumor transduced to secrete granulocyte-macrophage colony-stimulating factor. Cancer Gene Ther. 3: 39-47.

73. Ju DW, Cao X, Acres B. (1997) Intratumoral injection of GM-CSF gene encoded recombinant vaccinia virus elicits potent antitumor response in a murine melanoma model. (1997) Cancer Gene Ther. 4: 139144.

74. Qin H, Chatterjee SK. (1996) Cancer gene therapy using tumor cells infected with recombinant vaccinia virus expressing GMCSF. Hum. Gene Ther. 7: 1853-1860.

75. Ju DW, Cao X, Acres B. (1996) Active specific immunotherapy of pulmonary metastasis with vaccinia melanoma oncolysate prepared from granulocyte/macrophage-colony-stimulating-factor-gene-encoded vaccinia virus. J. Cancer Res. Clin. Oncol. 122: 716-722.

76. Fearon ER, Pardoll DM, Itaya T, Golumbek 
P, Levitsky HI, Simons JW, Karasuyama H, Vogelstein B, Frost P. (1990) Interleukin-2 production by tumour cells bypasses $T$ helper function in the generation of an antitumor response. Cell 60: 397-403.

77. Townsend SE, Allison JP. (1993) Tumor rejection after direct costimulation of CD8 + T cells by B7-transfected melanoma cells. Science 259: 368-370.

78. Chen L, McGowan P, Ashe S, et al. (1994) Tumor immunogenicity determines the effect of B7 costimulation on T cell-mediated tumor immunity. J. Exp. Med. 179: 523532.

79. Parker SE, Khatibi S, Margalith $M$, et al. (1996) Plasmid DNA gene therapy: Studies with the human interleukin-2 gene in tumor cells in vitro and in the murine B16 melanoma model in vivo. Cancer Gene Ther. 3: $175-185$.

80. Mahvi DM, Burkholder JK, Turner J, et al. (1996) Particle-mediated gene transfer of granulocyte-macrophage colony-stimulating factor CDNA to tumor cells: Implications for a clinically relevant tumor vaccine. 7: 1535-1543.

81. Yang JP, Huang L. (1996) Direct gene transfer to mouse melanoma by intratumor injection of free DNA. Gene Ther. 3: 542-548.

82. Kim TS, Russell SJ, Collins MKL, et al. (1992) Immunity to B 16 melanoma in mice immunized with IL-2-secreting allogeneic mouse fibroblasts expressing melanoma-associated antigens. Int. J. Cancer 51: 283-289.

83. Zoeten EV, Sun T, Cohen EP. (1997) Abstract 4243: Transfection of genomic DNA from murine melanoma cells into interleukin-2 secreting semi-allogeneic mouse fibroblasts results in a cellular immunogen that can prolong the lives of mice with melanoma. Proc. Am. Assoc. Cancer Res. 38: 632.

84. Quinton-Colonna F, Devauchelle P, Fradelizi D, et al. (1996) Gene therapy of spontaneous canine melanoma and feline fibrosarcoma by intratumoral administration of histoincompatible cells expressing human interleukin-2. Gene Ther. 3: 1104-1112.

85. Hollingsworth SJ, Darling D, Gaken J, et al. (1996) Abstract 1: The effect of combined expression of interleukin-2 and interleukin- 4 on the tumorgenicity and treatment of Bl6F10 melanoma. Br. J. Cancer 74: 615.

86. Kato K, Yamada K, Wakimoto H. (1995) Abstract P-30. Combination gene therapy with B7 and IL-12 for lung metastasis of mouse lung carcinoma. Cancer Gene Ther. 2: 316.

87. Abdel-Wahab Z, Dar M, Osanto S, et al. (1997) Eradication of melanoma pulmonary metastases by immunotherapy with tumor cells engineered to secrete interleukin-2 or gamma interferon. Cancer Gene Ther. 4: 33-41.

88. Cao X, Chen G, Zhang W, et al. (1996) Enhanced efficacy of combination of IL-2 gene and IL- 6 gene-transfected tumor cells in the treatment of established metastatic tumors. Gene Ther. 3: 421-426.

89. Nowak J, Cohen EP, Graf LH, Jr. (1991) Cytotoxic activity toward mouse melanoma following immunization of mice with transfected cells expressing a human melanomaassociated antigen. Cancer Immunol. Immunother. 33: 91-96.

90. Khokha R. (1994) Suppression of the tumorigenic and metastatic abilities of murine B16-F10 melanoma cells in vivo by the overexpression of the tissue inhibitor of the metalloproteinases-1. J. Natl. Cancer Inst. 86: 299-304.

91. Oku T, Tjuvajev J, Miyagawa T, et al. (1997) Abstract 1170: Modulation of intracerebral human melanoma xenografts growth by sense and anti-sense VEGF gene therapy: Effects on angiogenesis, vascular permeability, and tumor proliferation. Proc. Am. Assoc. Cancer Res. 38: 175.

92. Ohkawa T, Suzuki T, Irie A, et al. (1997) Adenoviral-mediated delivery of an anti-Hras hammerhead ribozyme in athymic mice bearing human malignant melanoma. Proc. Am. Assoc. Cancer Res. 38: 175.

93. Elder EM, Lotze MT, Whiteside TL. (1996) Abstract 16: Successful culture and selection of cytokine gene-modified human dermal fibroblasts for the biologic therapy of patients with cancer. Hum. Gene Ther. 7: 479-487.

94. Dessureault S, Graham F, Gallinger S. (1997) Abstract 75: Efficient adenoviralmediated B7-l gene transfer in freshly resected human tumors. Proc. Am. Assoc. Cancer Res. 38: 12.

95. Hersh EM, Stopeck AT, Brailey J, et al. (1997) Transduction of fresh and cultured human tumor cells with adenovirus expressing $\beta$-galactosidase. In press.

96. Arthur JF, Butterfield LH, Roth MD, et al. (1997) Abstract 14: A comparison of gene 
transfer methods in human dendritic cells. Gene Ther. 4: 17-25.

97. Zitvogel L, Couderc B, Mayordomo JI, et al. (1996) IL-12-engineered dendritic cells serve as effective tumor vaccine adjuvants in vivo. Ann. N Y Acad. Sciences 795: 284293.

98. Hersh EM, Stopeck AT, Warnecke J, et al. (1996) Abstract P-28: In vitro studies of tumor cell transfection with plasmid DNA in a cationic lipid vector. Cancer Gene Ther. 3: S18.

99. Clark PR, Stopeck AT, Wang Q, et al. (1996) Abstract P-48: Enhanced adenoviral transduction and transgene expression in vitro using polycations and cationic lipids. Cancer Gene Ther. 3: S23.

100. Albertini MR, Emler CA, Schell K, et al. (1996) Dual expression of human leukocyte antigen molecules and the B7-1 costimulatory molecule (CD80) on human melanoma cells after particile-mediated gene transfer. Cancer Gene Ther. 3: 192-201.

101. Parkhurst MR, Kang X, Rosenberg SA, et al. (1997) Abstract 1618: Induction of tumor reactive CTL using cos or B cells transfected with genes encoding the melanoma antigens MART-1 or gp100. Proc. Am. Assoc. Cancer Res. 38: 241.

102. Uchiyama A, Hoon DS, Morisaki T, et al. (1993) Abstract 5: Transfection of interleukin-2 gene into human melanoma cells augments cellular immune response. Cancer Res. 53: 949-952.

103. Arienti F, Sule-Suso J, Melani C, et al. (1994) Interleukin-2 gene-transduced human melanoma cells efficiently stimulate MHC-unrestricted and MHC-restricted autologous lymphocytes. Hum. Gene Ther. 5: 1139-1150.

104. Finke S, Trojaneck B, Moller P, et al. (1997) Increase of cytotoxic sensitivity of primary human melanoma cells transfected with the interleukin-7 gene. Cancer Gene Ther. 4: in press.

105. Morecki S, Karson E, Cornetta K, et al. (1991) Retrovirus-mediated gene transfer into CD4+ and CD8+ human T cell subsets derived from tumor-infiltrating lymphocytes and peripheral blood mononuclear cells. Cancer Immunol. Immunother. 32: 342352.

106. Royal RE, Reeves ME, Rosenberg SA, et al. (1997) Abstract 1567: Dendritic cells transduced with the gene encoding GP100 gen- erate specific anti-melanoma T cells. Proc. ASCO 16: 437a.

107. Anonymous. (1996) Clinical protocols worldwide. Cancer Gene Ther. 3: 265-278.

108. Anonymous. (1995) Section III: Gene therapy clinical trials worldwide. http://www. appleton-lange.com/genetherapy/trials. In: Sobol RE, Scanlon KJ (eds). The Internet Book of Gene Therapy/Cancer Therapeutics. Appleton and Lange, Stamford, CT, pp. 283-296.

109. Marcel T, Grausz JD. (1997) The TMC Worldwide Gene Therapy Enrollment Report, End 1996. Hum. Gene Ther. 8: 775800.

110. Rosenberg SA, Aebersold Paul, Cornetta K, et al. (1990) Gene transfer into humansImmunotherapy of patients with advanced melanoma, using tumor-infiltrating lymphocytes modified by retroviral gene transduction. New Engl. J. Med. 323: 570-578.

111. Rosenberg SA. (1993) Meeting Abstract 30: Gene therapy of cancer. Specific Immunotherapy of Cancer with Vaccines. January 2124, 1993, Washington, DC.

112. Cai Q, Rubin JT, Lotze MT. (1995) Genetically marking human cells-Results of the first clinical gene transfer studies. In: Sobol $\mathrm{RE}$, Scanlon KJ (eds). The Internet Book of Gene Therapy/Cancer Therapeutics. Appleton and Lange, Stamford, CT, pp. 163-174.

113. Merrouche $Y$, Negrier S, Bain C, et al. (1995) Abstract 7: Clinical application of retroviral gene transfer in oncology: Results of a French study with tumor-infiltrating lymphocytes transduced with the gene of resistance to neomycin. J. Clin. Oncol. 13: 410-418.

114. Licht T, Pastan I, Gottesman MM, et al. (1996) Abstract 5: The multidrug-resistance gene in gene therapy of cancer and hematopoietic disorders. Ann. Hematol. 72: 184-193.

115. Koc ON, Allay JA, Lee K, et al. (1996) Abstract 82: Transfer of drug resistance genes into hematopoietic progenitors to improve chemotherapy tolerance. Semin. Oncol. 23: 46-65.

116. Rankin EM, Kremers B, Gallee $M$, et al. (1997) Abstract 1760: Immunomodulation following vaccination with autologous, GM-CSF transduced and irradiated tumor cells in patients with advanced melanoma. Proc. ASCO. 16: 489a.

117. Soiffer R, Lynch T, Mihm M, et al. (1997) 
Abstract 1759: Induction of anti-tumor immunity by autologous melanoma vaccines genetically engineered to secrete granulocyte-macrophage colony-stimulating factor (G-CSF). Proc. ASCO. 16: 489a.

118. Nemunaitis J, Bohart C, Fong $T$, et al. (1997) Abstract 1774: Phase I trial of retroviral vector-mediated $\gamma$-interferon $(\gamma$-IFN) gene transfer into autologous tumor cells in patients with metastatic melanoma. Proc. $A S C O$. 16: 492a.

119. Abdel-Wahab ZA, Osanto S, Darrow TL, et al. (1994) Abstract 45: Transduction of human melanoma cells with the gamma interferon gene enhances cellular immunity. Cancer Gene Ther. 1: 171-179.

120. Tahara H, Zitvogel L, Storkus WJ, et al. (1997) Abstract 1568: Antitumor effects in patients with melanoma, head and neck and breast cancer in a phase I/II clinical trial of interleukin-12 (IL-12) gene therapy. Proc. ASCO. 16: 438a.

121. Suminami Y, Elder EM, Lotze MT, et al. (1995) Abstract 85: In situ interleukin-4 gene expression in cancer patients treated with genetically modified tumor vaccine. J. Immunother. Emphasis Tumor Immunol. 17: 238-248.

122. Meyers ML, Minasian L, Motzer RJ, et al. (1997) Abstract 1581: Immunization with HLA-A2 matched allogeneic tumor cells that secrete interleukin-2 of (IL-2) patients with metastatic melanoma or metastatic renal cell carcinoma. Proc. ASCO. 16: 441 a.

123. Osanto $S$, Weijl N, Brouwenstijn $N$, et al. (1994) Meeting abstract 61: Gene therapy of melanoma patients. Gene Ther. 1(Suppl 2): $S 17$.

124. Arienti F, Sule-Suso J, Belli F, et al. (1996) Abstract 70: Limited anti-tumor $\mathrm{T}$ cell response in melanoma patients vaccinated with interleukin-2 gene-transduced allogeneic melanoma cells. Hum. Gene Ther. 7: 1955-1963.

125. Mastrangelo MJ, Maguire HA, Jr, McCue PA. (1995) Abstract 107: Localized gene therapy for melanoma using vaccinia vectors: Anti-vaccinia immunity does not prevent tumor infection/transfection following repeated injections. Proc. Annu. Meet. Am. Assoc. Cancer Res. 36: A2751.

126. Lattime EC, Maguire HC, Jr, Eisenlohr LC, et al. (1997) Abstract 71: Gene therapy using intratumoral (IT) recombinant GM-CSF encoding vaccinia virus in patients with melanoma. Proc. Am. Assoc. Cancer Res. 38: 11.

127. Nemunaitis $\mathrm{J}$, Fong $\mathrm{T}$, Sajjadi $\mathrm{N}$, et al. (1997) Abstract 1590: Phase I trial of $\gamma$ interferon $(\gamma$-IFN) retroviral vector to administered intra-tumor to patients with metastatic carcinoma. Proc. ASCO. 16: 443a.

128. Felgner PL. (1997) Improvements in cationic liposomes for in vivo gene transfer (editorial). Hum. Gene Ther. 7: 1791-1793.

129. Nabel GJ, Nabel EG, Yang ZY, et al. (1993) Direct gene transfer with DNA-liposome complexes in melanoma: Expression, biologic activity and lack of toxicity in humans. Proc. Natl. Acad. Sci. USA 90: 1130711311.

130. Nabel GJ, Gordon D, Bishop DK, et al. (1996) Immune response in human melanoma after transfer of an allogeneic class I major histocompatibility complex gene with DNA-liposome complexes. Proc. Natl. Acad. Sci. USA 93: 15388.

131. DeBruyne LA, Chang AE, Cameron MJ, et al. (1996) Direct transfer of foreign MHC gene into human melanoma alters $\mathrm{T}$ cell receptor $\mathrm{V} \beta$ usage by tumor infiltrating lymphocytes. Cancer Immunol. Immunother. 43: 49-58.

132. Stopeck AT, Hersh EM, Akporiaye ET, et al. (1997) Phase I study of direct gene transfer of an allogeneic histocompatibility antigen, HLA-B7, in patients with metastatic melanoma. J. Clin. Oncol. 15: 341-349.

133. Rubin J, Galanis E, Pitot HC, et al. (1997) Phase I study of immunotherapy of hepatic metastases of colorectal carcinoma by direct gene transfer of an allogeneic histocompatibility antigen, HLA-B7. Gene Ther. 4: 419425.

134. Vogelzang NJ, Sudakoff G, McKay S, et al. (1995) A phase I study of intra-lesional (IL) gene therapy in metastatic renal cell cancer (RCC). Proc. Am. Soc. Clin. Oncol. 14: 242.

135. Akporiaye ET, Schluter S, Harris DT, et al. (1995) Abstract 1308: Expression of intratumorally injected HLA-B7 gene: Results from a phase I clinical trial. Proc. Am. Assoc. Cancer Res. 36: 220.

136. Harris D, Akporiaye E, Schluter S, et al. (1995) Abstract 1312: Direct gene transfer of histocompatibility antigens for immunotherapy of melanoma, colon and renal cancers. Proc. Am. Assoc. Cancer Res. 36: 220.

137. Silver HKB, Klasa RJ, Bally MB, et al. (1996) Phase I gene therapy study of 
HLA-B7 transduction by direct injection in malignant melanoma. Proc. Am. Assoc. Cancer Res. 37: 342.

138. Hersh EM, Nabel G, Silver H, et al. (1996) Abstract 0-1: Intratumoral injection of plasmid DNA in cationic lipid vectors for cancer gene therapy. Cancer Gene Ther. 3: S11.

139. Heo DS, Yoon SJ, Kim WS, et al. (1996) Abstract 0-2: Locoregional response and increased NK activity after intratumoral gene therapy with HLA-B7/ $\beta_{2}$-microglobulin gene. Cancer Gene Ther. 3: S1l.

140. Wahl WL, Strome SE, Nabel GJ, et al. (1995) Generation of therapeutic T-lym- phocytes after in vivo tumor transfection with an allogeneic class I major histocompatibility complex gene. J. Immunother. 17: 1 .

141. Stopeck A, Hersh E, Warneke J. (1996) Abstract 577: Results of a phase I study of direct gene transfer of interleukin-2 (IL-2) formulated with cationic lipid vector, leuvectin, in patients with metastatic solid tumors. Proc. ASCO 15: 235.

142. Orkin SH, Motulsky AG (1996) Report and recommendations of the Panel to Assess the NIH Investment in Research on Gene Therapy. NIH Home Page, http//www.nih. gov/news/panelrep.html, pp 1-45. 